\section{Conservative restorations}

that are made to last

Patients who choose restorative treatment want it to last. They also want it delivered with materials that facilitate minimal invasion to their healthy dentition, to avoid any compromise to the other teeth.

COLTENE's restorative materials can be used to deliver conservative restorations of excellence. They include all-round, great value options, such as BRILLIANT EverGlow and the new BRILLIANT Componeer, for efficient treatment chairside.

COLTENE's materials are marketleading because they handle well, the aesthetics are stunning, and they exhibit great versatility in a number of situations.

To find out why you should switch, browse the entire range online, then call COLTENE.

For more on COLTENE, visit www. coltene.com, emailinfo.uk@coltene.com or call 08002545115.

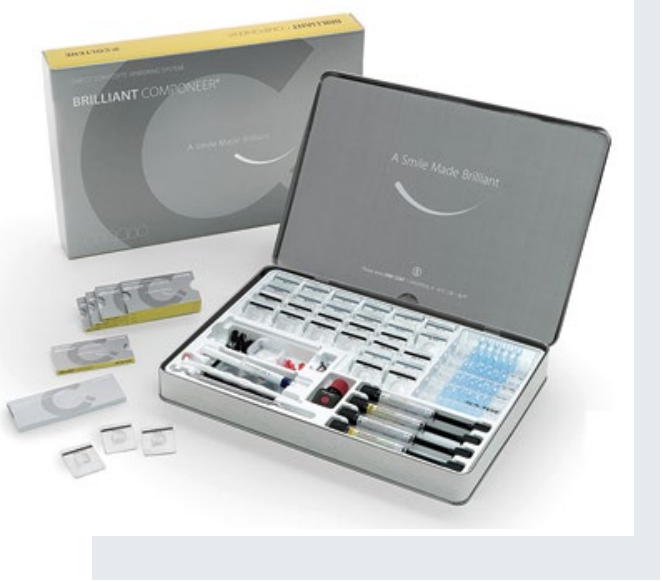

\section{Floss in the shower}

For a more convenient and effective oral hygiene routine, introduce your patients to the Waterpik Cordless Advanced Water Flosser. This lightweight, waterproof model can be used in the shower to effectively remove hard to reach bacteria deep between the teeth and below the gumline.

To establish a quick and easy way for your patients to floss, contact Waterpik today.

For more information on Waterpik products visit www.waterpik.co.uk.

Waterpik products are available from Amazon, Asda, Costco UK, Argos, Boots, Superdrug online and in stores across the UK and Ireland.
Book a free Waterpik Professional Lunch and Learn for one hour of CPD available either as a face to face meeting or a webinar. Visit www. waterpik.co.uk/ professional/ lunch-learn/.

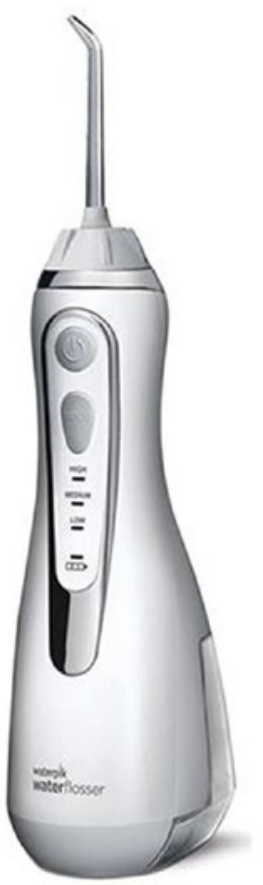

\section{Christmas with a difference}

Remind your patients that Curaprox oral healthcare products can make inexpensive yet practical additions to any Christmas stocking or DIY advent calendar.

Curaprox offers a diverse and colourful selection of CPS interdental brushes and CS 5460 ultra-soft manual toothbrushes. These can be combined with the 'Be you' range of fluoride toothpastes, which are available in six bold flavours.

You can also recommend the Hydrosonic Easy electric toothbrush - now available in a festive sleeve - to patients who are looking to bestow an even more impactful gift on a loved one this Christmas.

Rest assured that Curaprox products are designed to facilitate a gentle and effective clean for optimal oral health. Call now to order.
For more information call 01480 862084, email info@curaprox.co.uk or visit www.curaprox.co.uk.

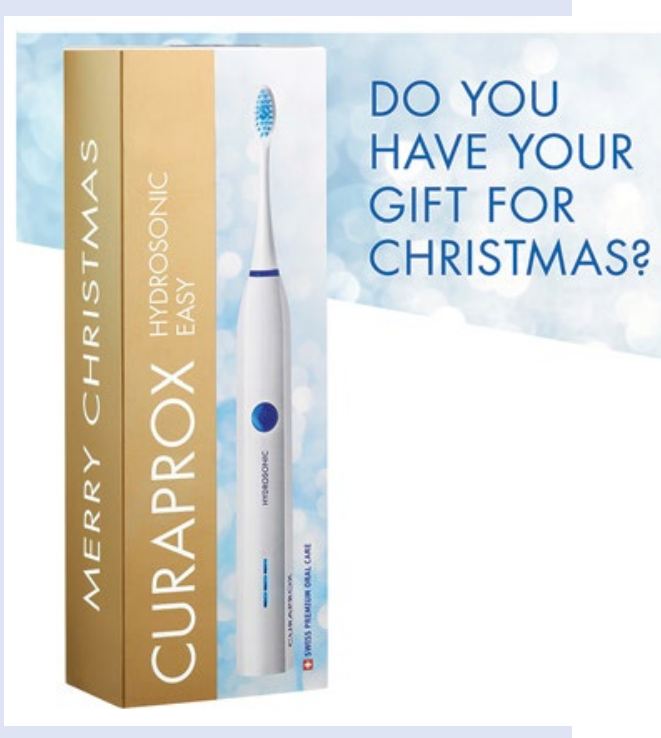

\title{
What does the future of dentistry look like?
}

Dentally is undertaking its annual 'State of Dentistry' survey and is asking as many dental practitioners, practice owners, managers and all those who work in the profession to take part.

In a year of unprecedented and challenging times that have changed the way we live and work, the world of dentistry has had to transform the way it operates. This survey looks to assess how our industry is responding to the pressures that COVID-19 has created. Dentally is keen to understand how practitioners and practices are coping with the changing demands and hear their thoughts on what the future may look like.

Your views really do count; you are all critical to the health of the dental industry, upholding standards and excellence in the profession, creating jobs, investment and innovation that will drive the sector forward.
To take part, simply visit https:// www.surveymonkey.co.uk/r/ stateofdentistry2020.

As a thank you for your participation you will be entered into a prize draw. The first completed survey chosen at random will receive a $£ 100$ Amazon voucher (no cash alternative and nontransferable). The closing date is 11 December 2020.

https://dentally.co/ 